\title{
Monoclonal antibody 4C5 prevents activation of MMP2 and MMP9 by disrupting their interaction with extracellular HSP90 and inhibits formation of metastatic breast cancer cell deposits
}

\author{
Dimitris Stellas ${ }^{1}$, Avraam El Hamidieh¹, Evangelia Patsavoudi ${ }^{1,2^{*}}$
}

\begin{abstract}
Background: Heat shock protein 90 (HSP90) is a molecular chaperone that is considered a new target for the treatment of cancer. Increasing data reveal an extracellular chaperoning activity for HSP90. Here we investigate the interaction of the secreted isoforms of HSP90 with matrix metalloproteinases (MMP) MMP2 and MMP9. Moreover we examine the role of a monoclonal antibody (mAb) against HSP90, mAb 4C5, regarding these interactions and its value as a potential inhibitor of human breast cancer cell invasion and metastasis.

Results: Our results showed that both HSP90 $\alpha$ and HSP90 $\beta$ are secreted by MDAMB453 human breast cancer cells and interact with MMP2 and MMP9. MAb 4C5, while not affecting the secretion of inactive MMPs, inhibits their activation by disrupting their interaction extracellularly with both isoforms of HSP90. The in vivo studies revealed that mAb 4C5 significantly inhibits the metastatic deposit formation of MDAMB453 cells into the lungs of SCID mice.

Conclusion: Both isoforms of HSP90 are secreted by MDAMB453 cells and interact with MMP2 and MMP9. MAb 4C5 prevents MMP2 and MMP9 activation, by disrupting their interaction with HSP90. Finally mAb 4C5 significantly inhibits the metastatic deposit formation of MDAMB453 cells, by preventing their extravasation and infiltration in the lung tissue and therefore it could be used as a potential therapeutic agent for cancer metastasis.
\end{abstract}

\section{Background}

The dissemination of tumor cells from their primary site of growth to distant organs is the major cause of morbidity and death among cancer patients $[1,2]$. Thus, inhibition of invasion and metastasis of cancer cells is of great importance in the treatment of cancer. Cancer cell invasion and metastasis is considered to be a complex, multi-step process, during which malignant cells detach from their point of origin, migrate and invade surrounding tissues, enter the vasculature, circulate and reach secondary sites, extravasate and establish metastatic foci $[3,4]$.

One well-characterized property of invasive tumors is their ability to accelerate the degradation of the

\footnotetext{
* Correspondence: epatsavoudi@pasteur.gr

'Department of Biochemistry, Hellenic Pasteur Institute, 127 Vasilissis Sofias
} Ave., 11521 Athens, Greece

extracellular matrix, by matrix metalloproteinases (MMPs) [5].This degradation provides access to the vasculature and lymphatic system, allowing tumor dissemination. MMPs have increased expression and activation in almost all human cancers[6]. More specifically, MMP2 and MMP9 are of particular interest because in addition to gelatin they degrade type IV collagen, the basic component of the basement membrane, which is the main barrier separating in situ and invasive carcinoma $[7,8]$.

The heat shock protein 90 (HSP90) is a molecular chaperone which exists in mammalian cells in two isoforms that share $86 \%$ aminoacid conservation (HSP90 $\alpha$ and HSP90ß). It is one of the most abundant cytoplasmic proteins in unstressed cells, where it performs housekeeping functions, controlling the activity, intracellular disposition and proteolytic turnover of a variety of proteins. Over the past years there has been increasing 
evidence that HSP90 interacts with a great number of molecules intracellularly, that are involved in the development and/or survival of cancer cells [9-11], allowing mutant proteins to retain or gain function, while permitting cancer cells to tolerate the imbalanced signaling that such oncoproteins create. Recently, we and others have identified a pool of HSP90 at the cell surface, where it was shown to be involved in cancer cell invasion [12]. Additionally, we have reported results showing that a monoclonal antibody (mAb) recognizing both the $\alpha$ and the $\beta$ isoforms of HSP90, mAb 4C5, inhibits melanoma cell invasion and metastasis by binding selectively to the surface pool of HSP90 [13]. Finally, we have presented data indicating that surface HSP90 interacts specifically with the extracellular domain of HER-2 and that this interaction which is necessary for the receptor's activation leading to breast cancer cell invasion, is disrupted by mAb 4C5 [14].

Taking all the above into consideration together with previous data showing that HSP90 $\alpha$ is secreted from fibrosarcoma cells and promotes their invasive capacity through association with MMP2 [15], in the present work we sought to investigate the secretion of both the $\alpha$ and the $\beta$ isoforms of HSP90 in the conditioned medium of MDAMB453 human breast cancer cells and their possible interaction with MMP2 and/or MMP9. Furthermore and after taking into account our previously mentioned recent data showing that mAb 4C5 inhibits MDAMB453 human breast cancer cell invasion in vitro by disrupting the association of cell surface HSP90 with HER-2,[14] in this work we examined: a) the effect of mAb 4C5 on MMP2 and MMP9 secretion and activation b) the ability of this antibody to disrupt the interaction of extracellular HSP90 with MMP2 and/or MMP9 and c) the capacity of mAb $4 \mathrm{C} 5$ to inhibit in vivo, the formation of metastatic deposits of MDAMB453 cells in the lungs of SCID mice.

\section{Results}

Both the $\alpha$ and $\beta$ isoforms of HSP90 are secreted by MDAMB453 breast cancer cells and interact with MMP2 and MMP9

In order to investigate the secretion of the $\alpha$ and $\beta$ isoforms of HSP90 by MDAMB453 cells, cell lysates and concentrated supernatants derived from the culture of these cells were analyzed by Western blotting using $\mathrm{mAb} 4 \mathrm{C} 5$ which recognizes both isoforms of HSP90[16], and the commercially available anti-HSP90 $\alpha$ and anti-HSP90 $\beta$ antibodies. As shown in Figure 1A, both the $\alpha$ and the $\beta$ isoforms of HSP90 are secreted by MDAMB453 cells. The absence of beta actin in the supernatant fraction (Figure.1A) demonstrates that there is no contamination of the culture supernatants with the intracellular components of cells during the experimental procedure. At this point it is important to note that beta actin was never detected in any of the concentrated supernatants used in the experiments described hereafter (data not shown).

An important characteristic of invasive tumors is their capacity to accelerate the degradation of extracellular matrix by MMPs [5]. MMPs are secreted as inactive pro-enzymes and are activated extracellularly by proteolysis [17]. We thus next examined the possible interaction of the secreted pool of HSP90 with MMP2 and MMP9. After confirming the presence of both proMMP2 and pro-MMP9 as well as their activated forms in the culture medium of MDAMB453 cells (Figure.1B), we showed by immunoprecipitation experiments in the culture supernatant using anti-MMP2 and anti-MMP9 antibodies followed by Western blot analysis with antibodies against the $\alpha$ and $\beta$ isoforms of HSP90, that indeed both isoforms of HSP90 interact with the metalloproteinases examined (Figure.1B). In order to further clarify the interaction of extracellular HSP90 with the MMPs studied, reverse co-immunopercipitation experiments were performed. Our results showed that both the $\alpha$ and the $\beta$ isoforms of HSP90 interact with the inactive pro-MMP2 and pro-MMP9 (Figure.1C). Interaction with the mature forms of the corresponding metalloproteinases was also detected (Figure.1C).

\section{MAb4C5 prevents MMP2 and MMP9 activation and disrupts their interaction with both the $\alpha$ and the $\beta$ isoform of extracellular HSP90}

Based on our observation that presence of both the inactive and mature forms of MMP2 and MMP9 were detected in the concentrated supernatants derived from MDAMB453 cell cultures, we next examined the effect of mAb 4C5, the function blocking anti-HSP90 antibody, on the secretion and activation of MMP2 and MMP9. Analysis of concentrated supernatants derived from MDAMB453 cells, with zymography, showed that when $200 \mu \mathrm{g} / \mathrm{ml}$ of $\mathrm{mAb} 4 \mathrm{C} 5$ were included in the culture medium, presence of the inactive pro-enzymes was not affected, while detection of the activated forms of both MMPs was not obtained (Figure.2A). These results were confirmed using antibodies against the metalloproteinases, and western blot analysis (Figure.2B). At this point it is important to note that addition of $\mathrm{mAb} 4 \mathrm{C} 5$ in the culture medium did not affect secretion of HSP90 $\alpha$ or HSP90 $\beta$ (data not shown).

Consequently and taking into account the previously demonstrated interactions of both isoforms of HSP90 with MMP2 and MMP9, we explored the role of $\mathrm{mAb}$ $4 \mathrm{C} 5$ in relation to these interactions, using co-immunoprecipitation experiments. To this purpose, concentrated conditioned media derived either from control or $\mathrm{mAb}$ $4 \mathrm{C} 5$ treated cultures were immunoprecipitated with 


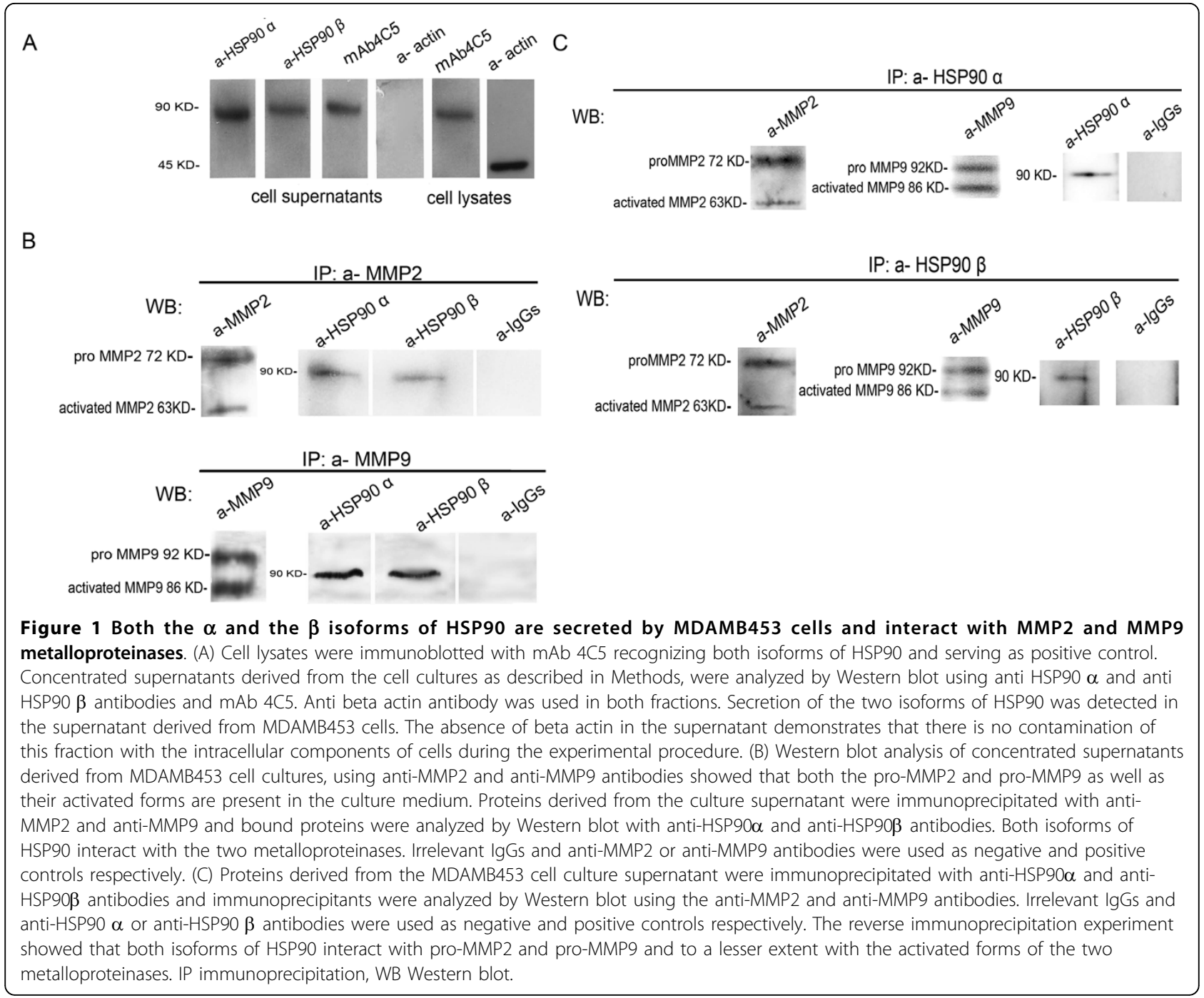

antibodies against MMP2 and MMP9 followed by Western blot analysis with antibodies against the $\alpha$ and the $\beta$ isoforms of HSP90. As shown in Figure $2 \mathrm{C}$, co-immunoprecipitation of both isoforms of HSP90 with the inactive forms of MMP2 and MMP9 was inhibited in the media derived from the cells cultured in the presence of mAb 4C5, when compared with control cultures. This result indicates that $\mathrm{mAb} 4 \mathrm{C} 5$ disrupts extracellularly the interaction of both pro-MMP2 and pro-MMP9 with the two isoforms of HSP90.

MAb4C5 inhibits the metastatic deposition of MDAMB453 breast cancer cells into the lungs of SCID mice

On the basis of previously reported studies using the MDAMB453 cell line [14] and showing that mAb 4C5 inhibits the invasion of these cells in vitro, we next sought to investigate the in vivo effect of mAb $4 \mathrm{C} 5$ on the metastatic behavior of this breast cancer cell line. Thus, we injected MDAMB453 cells labeled with the fluorescent dye DiI intravenously in SCID mice, either in the presence or in the absence of $100 \mu \mathrm{g} / \mathrm{ml}$ of $\mathrm{mAb}$ 4C5. Twenty four hours after the injection, mice were euthanized and the metastatic deposits of MDAMB453 cells were traced and evaluated in the lungs of both the control and the mAb 4C5 treated groups. At the macroscopic level an important number of metastatic cell deposits (arrow in Figure.3A) was observed in control animals as compared to $\mathrm{mAb} 4 \mathrm{C} 5$ treated mice. This was confirmed microscopically where a very important decrease in the deposition of cancer cells was detected in the $\mathrm{mAb} 4 \mathrm{C} 5$ treated mice (arrows in Figure.3B). Quantification of the metastatic deposit formation revealed a $86.67 \%$ inhibition in the mAb $4 \mathrm{C} 5$ treated mice when compared with control mice (Figure.3C). In order to further visualize the deposition of MDAMB453 cells in the lung tissue, we performed a $3 \mathrm{D}$ reconstitution of a cryosection derived from a control animal where the infiltration of metastatic deposits of 


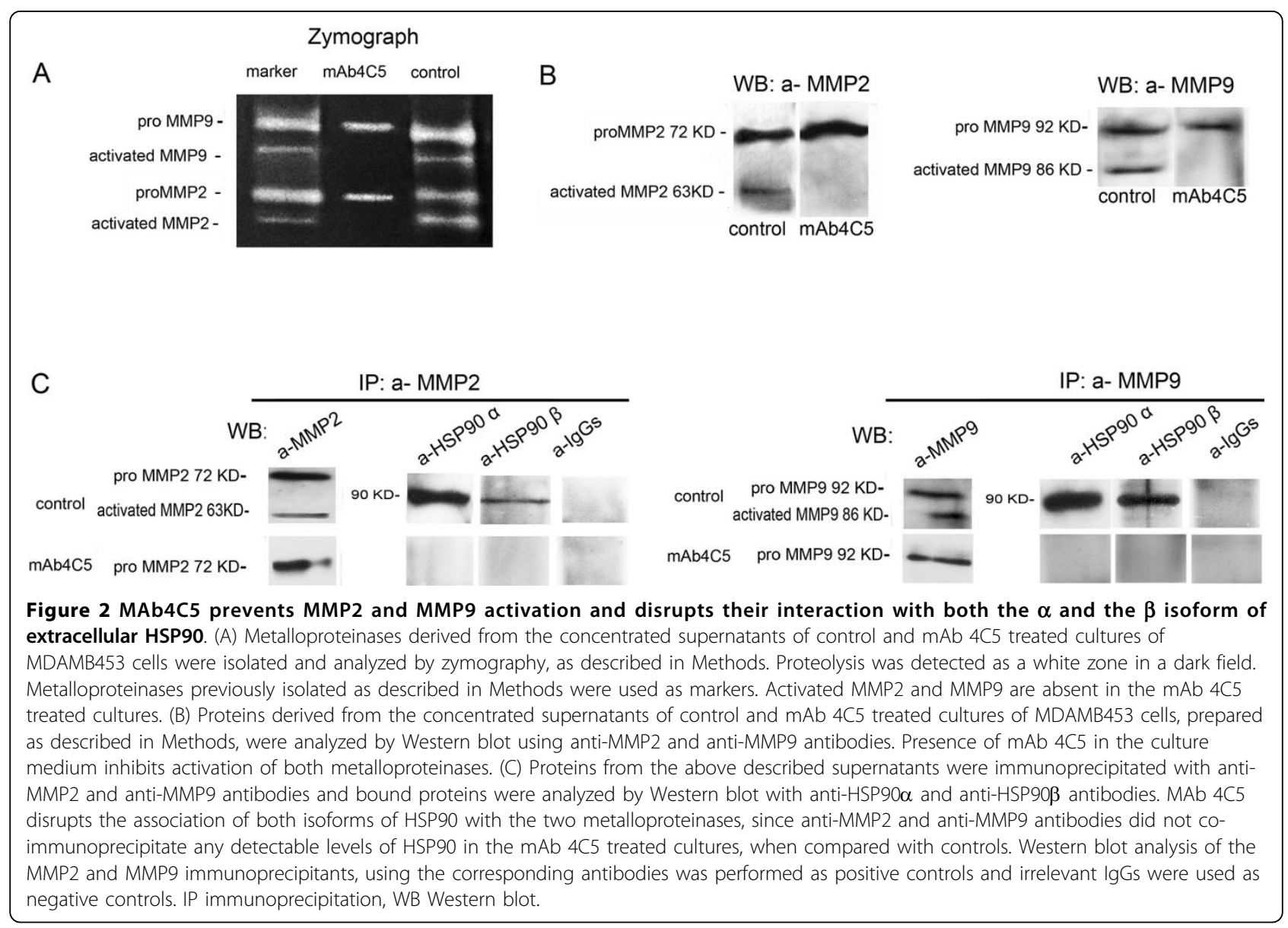

MDAMB453 cells in the lung tissue is clearly demonstrated (arrow in Figure.3D). It is of interest to note that in the mAb 4C5 treated mice, MDAMB453 cells were often observed stagnating on the inner surface of large pulmonary blood vessels whereas no such images could be detected in the control animals (arrows in Figure.3E). Quantification of this occurrence revealed that in $58.76 \%$ of the pulmonary vessels visualized in the, mAb4C5 treated animals, MDAMB453 cells were observed stagnating on the inner surface of the vessels. In contrast, only $15.4 \%$ of the vessels observed in the control animals showed intravascular retention of the cancer cells. (Figure 3F).

\section{Discussion}

Our present findings demonstrate that both the $\alpha$ and the $\beta$ isoforms of HSP90 are secreted by cultured MDAMB453 human breast cancer cells and interact with matrix metalloproteinases, MMP2 and MMP9. Additionally, we show that a monoclonal antibody against HSP90, mAb 4C5, prevents maturation of the two metalloproteinases in vitro and inhibits metastatic deposition of breast cancer cells in vivo.
We have previously reported the presence of HSP90 $\alpha$ and HSP90 $\beta$ on the cell surface of MDAMB453 breast cancer cells [14]. Here we further examined the extracellular localization of HSP90. More specifically, we demonstrated the secretion of both HSP90 $\alpha$ and HSP90 $\beta$ in the culture medium of MDAMB453 cells using antibodies specific for the two isoforms. At this point it is important to note that specificity of the antiHSP90 $\beta$ antibody was further confirmed since, Western blot analysis of human recombinant HSP90 $\alpha$ using this antibody gave negative results (see additional files 1 and 2). Our findings, for the first time to our knowledge, reveal secretion of HSP90 $\beta$ by breast cancer cells and are only partly in agreement with existing knowledge. Indeed, previous studies have reported secretion only of HSP90 $\alpha$ from various cell types including HT 1080 fibrosarcoma cells [15], human dermal fibroblasts under hypoxia conditions[18] and transforming growth factor alpha stimulated human keratinocytes [19]

Controlled degradation of the extracellular matrix is essential for the invasion and metastasis of malignant tumors. In this context matrix metalloproteinases and in particular MMP2 and MMP9 are of crucial significance 
A

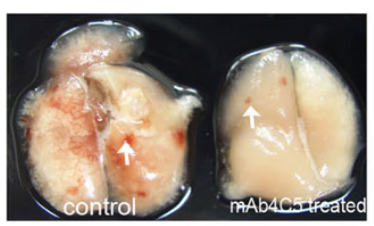

B

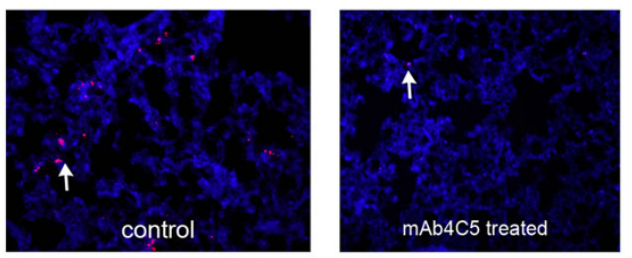

C

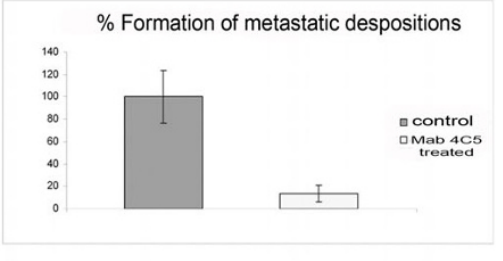

D

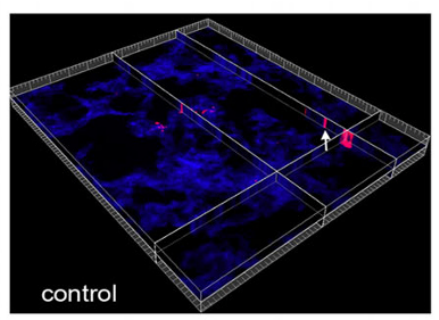

$\mathrm{E}$

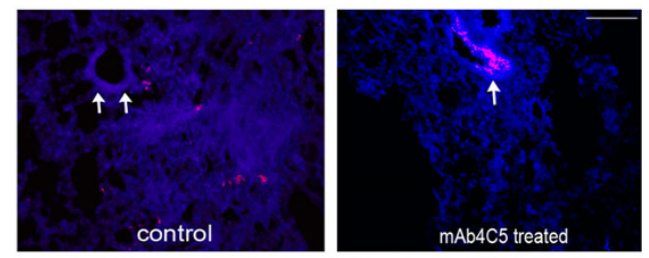

F

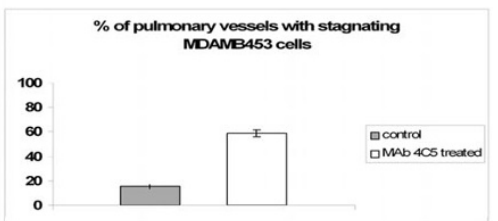

Figure 3 MAb 4C5 inhibits the metastatic deposition of MDAMB453 cancer cells into the lungs of SCID mice. MDAMB453 cells were labeled with the fluorescent dye Dil and injected into SCID mice, in the presence either of $100 \mu \mathrm{g} / \mathrm{ml}$ of mAb 4 C5 or of an irrelevant antibody (control), as described in Methods. Evaluation of metastatic deposits was performed several hours later. (A) Macroscopic level: An important number of metastatic deposits (arrow) was observed in control animals as compared to mAb 4C5 treated mice. (B) Microscopic level: Representative cryosections of the lungs of control and mAb 4C5 treated mice. The arrows show MDAMB453 cells stained with Dil present in the lung tissue. A significant decrease in the deposition of cancer cells was observed in the mAb4C5 treated mice. (C) Quantitative effect of mAb 4C5 on the metastatic deposition of MDAMB453 cells into the lungs showed an $86.67 \%$ inhibition of the metastatic deposition in the mAb 4C5 treated mice when compared to the control animals. (D) A 3D reconstitution of a cryosection from a control animal: The arrow demonstrates infiltration of metastatic deposits in the lung tissue. (E) MDAMB453 cells restrained in the inner surface of large pulmonary vessels derived from mAb 4C5 treated mice. On the contrary, in the lungs from control mice MDAMB453 cells could rarely be detected stagnating in the inner surface of the pulmonary vessels. However, cancer cells were clearly observed dispersed in the lung tissue. Arrows indicate the pulmonary vessels. (F) Quantitative effect of mAb 4C5 on the retention of MDAMB453 cells in the pulmonary vessels. A 15.4\% of the vessels visualized in the control animals showed intravascular cancer cell retention. In contrast in the mAb 4C5 treated mice, cancer cells were observed stagnating in the inner surface of $58.76 \%$ of the calculated vessels $(p<0.01 \mathrm{Bar}, 40 \mu \mathrm{m})$. 
for tumor development and progression [20]. Indeed increasing experimental evidence indicates involvement of both enzymes at multiple steps of the metastatic process[21] It is important to note that these metalloproteinases are secreted as inactive pro- enzymes and acquire their active form extracellularly $[3,22]$. Taking these into account together with accumulating data demonstrating extracellular activity of HSP90 [12], we next examined the possible interaction of this molecule with the two metalloproteinases using co-immunoprecipitation experiments. Our results showed that both the $\alpha$ and the $\beta$ isoforms of HSP90 interact with the secreted, inactive forms of MMP2 and MMP9. Interestingly, reverse co-immunoprecipitation experiments revealed that HSP90 also interacts, with the extracellularly activated forms of the two MMPs, The above observations indicate that HSP90 participates in the activation of MMP2 and MMP9. Moreover, they suggest a second level of chaperoning for this molecule associated with the mature forms of the metalloproteinases examined. Our findings are in accordance with previously reported data showing association of the secreted pool of HSP90 $\alpha$ with MMP2 $[15,23]$. Moreover they provide new evidence for a further increase in the number of clients of this chaperone molecule by adding MMP9 to the list of its extracellular substrates.

We have previously demonstrated that mAb 4C5 inhibits the invasive capacity of MDAMB453 breast cancer cells by disrupting the interaction of cell surface HSP90 with the extracellular domain of HER-2, a member of the ErbB family of epidermal growth factor receptors [14]. Taking this into account together with the above mentioned findings we next investigated whether $\mathrm{mAb}$ $4 \mathrm{C} 5$ independently of its effect on HER2 has also an effect on the secretion and activation of MMP2 and MMP9. Our results showed that when the cellimpermeable mAb 4C5 [14] is added to the culture medium of MDAMB453 cells, secretion of pro-MMP2 and pro-MMP9 is not affected; however and as shown by zymography and western blot analysis, the activation of these metalloproteinases is dramatically inhibited as compared to controls where mAb $4 \mathrm{C} 5$ is not included in the culture medium. Moreover, co-immunoprecipitation experiments performed as described in Methods, revealed that $\mathrm{mAb} 4 \mathrm{C} 5$ effectively disrupts the interaction of HSP90 with MMP2 and MMP9 respectively. Our present data indicate that $\mathrm{mAb} 4 \mathrm{C} 5$ while not affecting secretion of the inactive forms of MMP2 and MMP9, prevents their maturation most probably by disrupting their interaction with the extracellular pool of HSP90. Similar to our results have been previously reported by Eustace et al [15] who have shown that inhibition of extracellular HSP90 $\alpha$ decreases activation of MMP2. At this point it should be noted that preliminary experiments performed using the MDAMB231 breast cancer cells which lack the HER2 receptor, indicate not only that these cells too secrete both isoforms of HSP90 but also that MMP2 and MMP9 activation by extracellular HSP90 may be independent of the HER2/HSP90 interaction previously reported [14], since in this system as well $\mathrm{mAb} 4 \mathrm{C} 5$ prevented activation of these metalloproteinases (unpublished data). Nevertheless our overall observations do not exclude the possibility that in combination with HSP90 additional molecules, such as other HSPs, HSP90 co-chaperones etc may be necessary for the activation of the MMPs studied in this work. This however, needs further investigation.

We have previously demonstrated that mAb $4 \mathrm{C} 5$ significantly inhibits melanoma metastasis in C57BL/6 mice inoculated with B16 F10 melanoma cells, [13]. supporting accumulating data showing that antibodies or other small molecules that inhibit HSP90 can be used as anti-cancer agents [24] This prompted us to explore the anti-metastatic activity of mAb $4 \mathrm{C} 5$ with respect to MDAMB453 breast cancer cells. In line with the recently reported in vitro results [14], in this work we showed that $\mathrm{mAb}$ 4C5 strongly inhibits the metastatic depositions of MDAMB453 cells into the lungs of SCID mice. More specifically an $86.67 \%$ inhibition of metastatic depositions of MDAMB453 cells was observed in the mAb 4C5 treated mice as compared with control animals. It is interesting to note that in the experimental group of mice that received $\mathrm{mAb} 4 \mathrm{C5}$, MDAMB453 cells were often observed stagnating on the inner surface of large pulmonary vessels, whereas such a phenomenon was very rarely detected in the control mice. Quantification of this occurrence confirmed a statistically significant difference $(\mathrm{p}<0,001)$ between the two experimental groups. This remarkable observation together with the above mentioned data, tempts us to reason that mAb 4C5 exerts its activity by disrupting the interaction of extracellular HSP90 with MMP2 and MMP9 and thus preventing activation of these matrix metalloproteinases which, as is well documented $[7,8]$, is necessary for the degradation of type IV collagen, a major constituent of the basement membrane associated with the pulmonary blood vessel. As a consequence, tumor cells remain limited to the inner surface of the vessel and their infiltration into the lung tissue is impaired. Regulation of MMP activation has been previously correlated with cancer cell extravasation. In particular Cruz-Munoz et al have reported that TIMP-3 decreases MMP2 activation which in turn limits tumor cell extravasation and subsequent colonization of the lung[25].

\section{Conclusions}

Our present findings combined with recently reported data $[13,14]$, reinforce and further extend the idea that 
extracellular chaperoning of both the $\alpha$ and the $\beta$ isoforms of HSP90, at least in relation to cancer cell invasion and metastasis, is exerted at multiple levels such as activation of growth factor receptor as previously reported[14] and MMP2 and MMP9 activation. Our results additionally suggest that extracellular HSP90 may also chaperone the activity of the mature metalloproteinases with their corresponding substrates. However, elucidation of the precise molecular mechanisms underlying these interactions needs further investigation. Finally, our present work further demonstrates the antimetastatic capacity of mAb $4 \mathrm{C} 5$, showing that it inhibits not only melanoma metastasis [13] but also the formation of metastatic breast cancer cell deposits by preventing extravasation of tumor cells and their invasion in the lung tissue.

\section{Methods \\ Reagents}

MAb4C5 was produced and characterized, as previously reported [26]. In the present study, mAb4C5 was used as concentrated serum free supernatant dialyzed in saline buffer in all experiments performed. Polyclonal antibodies specific for the $\alpha$ and the $\beta$ isoforms of HSP90 were obtained from Chemicon. International, USA. At this point it should be noted that according to the manufacturer, the anti-HSP90 $\beta$ antibody shows no reactivity with HSP90 $\alpha$ and the anti-HSP90 $\alpha$ antibody reacts weakly with HSP90 $\beta$. Polyclonal antibody recognizing both the inactivated pro-enzyme and the activated form of human MMP2 was obtained from Chemicon. International, USA. Polyclonal antibody recognizing both the inactivated pro-enzyme and the activated form of human MMP9 was obtained from Santa Cruz Biotechnology INC. Monoclonal antibody against human beta actin was obtained from Santa Cruz Biotechnology INC Polyclonal biotinylated antibodies against anti-rabbit and anti mouse immunoglobulins were obtained from Dako Cytomation Denmark A/S. Human recombinant HSP90 $\alpha$ was a generous gift from Dr C. Prodromou, Institute of Cancer Research. Gelatin-agarose beads, used for the preclearing of the supernatants, as well as protein $\mathrm{G}$ and protein A-sepharose beads, used for the co-immunopercipitation experiments, were obtained from Sigma. Dulbecco's modified Eagles medium (DME), fetal bovine serum (FBS), RPMI, were obtained from Gibco, INC, USA.

\section{Cell cultures}

The MDAMB453 human breast cancer cell line was kindly provided by Dr A.Mamalaki from the Hellenic Pasteur Institute, Athens, Greece. The cells were seeded at a density of $2 \times 10^{6}$ cells per $\mathrm{cm}^{2}$ on plastic dishes as monolayers in RPMI media containing 10\% FBS and supplemented with the antibiotic garamycin, $(10 \mathrm{mg} / \mathrm{ml})$ in a $5 \% \mathrm{CO}_{2}$ humidified atmosphere at $37^{\circ} \mathrm{C}$. When cells reached confluence, the initial medium was replaced by RPMI without FBS and the cells were left for 24 hours in starvation conditions. Subsequently they were exposed to $200 \mu \mathrm{g} / \mathrm{ml}$ of $\mathrm{mAb} 4 \mathrm{C} 5$ for $24 \mathrm{~h}$. Control cultures were grown for $24 \mathrm{~h}$ either in RPMI medium alone or in culture medium containing $200 \mu \mathrm{g} / \mathrm{ml}$ of an irrelevant IgG2a monoclonal antibody named BM88 [27].

Preparation of cell lysates and concentrated supernatants At the termination of the cultures, cells were immediately washed twice with ice-cold PBS and lysed in $50 \mu \mathrm{l}$ lysis buffer $(137 \mathrm{mM} \mathrm{NaCl}, 20 \mathrm{mM}$ Tris/HCl pH 7.4, $50 \mathrm{mM}$ HEPES, $5 \mathrm{mM}$ EDTA, $1 \mathrm{mM}$ DTT, 1 \%Triton, 10 \%Glycerol, $200 \mathrm{mM} \mathrm{Na} 3 \mathrm{VO} 4,0.5 \mathrm{mM}$ PMSF, $5 \mu \mathrm{g} / \mathrm{ml}$ aprotinin, $5 \mu \mathrm{g} / \mathrm{ml}$ pepstatin and $50 \mu \mathrm{g} / \mathrm{ml}$ leupeptin). Protein lysates were quantified and equal amounts of total protein were subjected to SDS-PAGE and Western blot. Concentrated supernatants derived from MDAMB453 cells, cultured as described above, were prepared as follows: An initial volume of $20 \mathrm{ml}$ of culture supernatant was collected from each experimental case (control and mAb 4C5 treated cultures). At this point it is important to underline that the supernatants were derived from the same number of cultured cells, for all experimental cases. Subsequently 100 fold concentration was performed using ultra centrifugal filter devices (10000 MWCO) obtained from Millipore TM. The concentrated supernatants were used for all the experimental procedures concerning immunoprecipitations and Western blots. Equal volumes of the concentrated supernatants were subjected to SDS-PAGE on $12 \%$ acrylamide in order to obtain the best separating conditions for the proteins of interest [28]. The analyzed proteins were transferred to nitrocellulose membranes. For Western blots, membranes were incubated for $40 \mathrm{~min}$ at room temperature with non-fat dry milk (5\%) in TBS and were then incubated with specific primary antibodies overnight at $4^{\circ} \mathrm{C}$. The membranes were washed with $0.3 \%$ BSA in TBS and incubated with horseradish peroxidase-labeled secondary antibodies for $2 \mathrm{~h}$ at room temperature. After washing with TBS, the bound antibody complex was detected using an ECL chemiluminescence reagent (Amersham) and XOMAT - AR film (Kodak, Pittsburgh, PA, USA) as described by the manufacturers.

\section{Co-immunoprecipitation}

Co-immunoprecipitation was performed as previously described [29]. In brief, equal amounts of cellular lysates and equal volumes of the concentrated supernatants from control and $\mathrm{mAb} 4 \mathrm{C} 5$ treated cultures of MDAMB453 cells were incubated with antibodies 
overnight at $4^{\circ} \mathrm{C}$. The immunocomplexes were then incubated for $2 \mathrm{~h}$ at room temperature with protein G-Sepharose or protein A-Sepharose (for the mAb 4C5 treated cultures) and washed 3 times with lysis buffer. At this point it should be noted that mAb $4 \mathrm{C} 5$ does not bind to protein A Sepharose (unpublished observations) thus it's presence did not interfere with the immunoprecipitation process. Bound proteins were analyzed by gel electrophoresis and Western blot as described above.

\section{Isolation of metalloproteinases}

Isolation of the MMPs from the other proteins present in the concentrated supernatants was performed as previously described[30]. Briefly gelatin-Agarose beads were used in order to form two columns. The concentrated supernatants of the control and $\mathrm{mAb} 4 \mathrm{C} 5$ treated cultures were loaded on the two columns and washed with an equilibration buffer containing $0.05 \mathrm{M}$ Tris- $\mathrm{HCl}$ $\mathrm{pH}: 7,5 / 0.5 \mathrm{M} \mathrm{NaCl}$, and $0.1 \%$ Triton X-100. Gelatine bound MMPs were eluted with equilibration buffer containing $1 \mathrm{M} \mathrm{NaCl}$ and $5 \%(\mathrm{v} / \mathrm{v})$ dimethyl sulphoxide.

\section{Zymographs}

Equal volumes of isolated MMPs derived from control and mAb 4C5 treated cultures of MDAMB453 cells, were denatured and analyzed by gel electrophoresis in a $10 \%$ SDS-polyacrylamide gel containing $0.1 \%(\mathrm{w} / \mathrm{v})$ gelatin. The gel was incubated at room temperature for $2 \mathrm{~h}$ in the presence of $2.5 \%$ Triton $\mathrm{x}-100$ and subsequently at $37^{\circ} \mathrm{C}$ over night in a buffer containing $10 \mathrm{mM} \mathrm{CaCl}_{2}$, $0.15 \mathrm{M} \mathrm{NaCl}$, and $50 \mathrm{mM}$ Tris $(\mathrm{pH} 7.5)$. The gel was then stained for protein with $0.5 \%(\mathrm{w} / \mathrm{v})$ Coomassie and photographed on a light box. Proteolysis was detected as a white zone in a dark field. MMPs (proenzymes and active forms) isolated as previously described [30] from extracts of interface tissue from loose hip arthroplasty endoprostheses were used as markers (kindly provided by Dr Aletras).

\section{Assay of MDAMB453 cell metastatic deposit formation in the lung tissue}

SCID mice were originally purchased from Jackson Laboratory, bred and maintained under specific pathogen free conditions at the Experimental Animal Unit of the Hellenic Pasteur Institute. All of the experiments with animals were done in accordance with the guidelines approved by the Ethical Committee of the Hellenic Pasteur Institute. The in vivo metastatic deposit formation assay, was performed as previously described [31,17] Briefly, cultured MDAMB453 cells were preincubated with DiI for 1 hour, washed twice with PBS, trypsinized and made up to the cell density of $10^{6} /$ $300 \mu \mathrm{L}$ in PBS in the absence or presence of $100 \mu \mathrm{g} / \mathrm{ml}$ of an irrelevant antibody named of mAb BM88[27] or
$100 \mu \mathrm{g} / \mathrm{ml}$ of mAb 4C5. Twenty 8- 10-week-old female SCID mice were injected through the tail vein with $0.3 \mathrm{ml}$ of the above cell preparations. The animals were divided into two equal groups: the control group injected with cells dialysed in PBS or the irrelevant antibody, mAb BM88 and the mAb $4 \mathrm{C} 5$ treated group. The animals were euthanized 24 hours later and with the use of a peristaltic pump connected to the left ventricle of the heart, their lungs were completely washed from the remaining blood, by pumping $200 \mathrm{ml}$ of saline buffer. This procedure ensures that all cancer cells which are not attached, either on the inner surface of the blood vessels or on the lung tissue, are removed. Finally the lungs were perfused with $4 \%$ formalin solution and then embedded in OCT solution in order to perform cryosections. Each lung was sectioned with the cryotome and each section was counter stained with Dapi and visualised with a confocal microscope. In ten randomly chosen slides covering the whole of the lung tissue the MDAMB453 cells were calculated. The same experiment was performed twice with similar results.

\section{Evaluation of tumor cell retention in the pulmonary vessels}

In the above mentioned lung sections the total number of blood vessels was calculated and MDAMB453 stagnating cells were visualized and compared between the control and the mAb $4 \mathrm{C} 5$ treated animals.

\section{Statistical analysis}

For the experimental groups that were statistically analyzed for differences, Student's t test was used, in which $p<0.05$ was defined as statistically significant.

\section{Additional material}

Additional file 1: Additional figure showing that the antibody against HSP90 $\beta$ does not recognize the HSP90 $\alpha$ isoform. The western blot analysis of human recombinant HSP90 $\alpha$ and total cell lysates (positive control) derived from MDAMB453 cell cultures using anti-HSP90 $\alpha$ (positive control) and anti-HSP90 $\beta$ antibodies.

Additional file 2: Additional figure legend. A file containing the legend of the additional figure.

\section{Acknowledgements}

We wish to thank Dr A. Aletras for precious advice concerning the zymography experiments and for providing the metalloproteinase markers, Dr A. Mamalaki for providing the MDAMB453 cell line, Dr C. Prodromou for his generous gift of recombinant HSP90 $\alpha$ and Dr K. Sidera for critically reading the manuscript. This project was supported by the European Social Fund and National Resources-(EPEAEKII-Archimides).

\section{Author details}

${ }^{1}$ Department of Biochemistry, Hellenic Pasteur Institute, 127 Vasilissis Sofias Ave., 11521 Athens, Greece. ${ }^{2}$ Department of Medical Instrumentation, Technological Educational Institution of Athens, Ag. Spyridonos str., Egaleo, 12210 Athens, Greece. 


\section{Authors' contributions}

DS participated in the design of the study carried out, part of the i.p. experiments, the in vivo experiments and the statistical analysis. Moreover he participated in the drafting of the manuscript. AH performed part of the i. p. experiments and the zymography. EP conceived of the study, oversaw the experimental design and wrote the final draft of the manuscript. All authors read and approved the final manuscript.

Received: 7 September 2009 Accepted: 5 July 2010 Published: 5 July 2010

\section{References}

1. Chambers AF, Groom AC, MacDonald IC: Dissemination and growth of cancer cells in metastatic sites. Nat Rev Cancer 2002, 2:563-72.

2. Friedl P, Wolf K: Proteolytic and non-proteolytic migration of tumour cells and leucocytes. Biochem Soc Symp 2003, 277-85.

3. Curran S, Murray GI: Matrix metalloproteinases in tumour invasion and metastasis. J Pathol 1999, 189:300-8.

4. Hanahan D, Weinberg RA: The hallmarks of cancer. Cell 2000, 100:57-70.

5. Liotta LA, Tryggvason K, Garbisa S, Hart I, Foltz CM, Shafie S: Metastatic potential correlates with enzymatic degradation of basement membrane collagen. Nature 1980, 284:67-8.

6. Lopez-Otin C, Overall CM: Protease degradomics: a new challenge for proteomics. Nat Rev Mol Cell Biol 2002, 3:509-19.

7. Itoh Y, Takamura A, Ito N, Maru Y, Sato H, Suenaga N, Aoki T, Seiki M: Homophilic complex formation of MT1-MMP facilitates proMMP-2 activation on the cell surface and promotes tumor cell invasion. Embo J 2001, 20:4782-93.

8. Hamano Y, Zeisberg M, Sugimoto H, Lively JC, Maeshima Y, Yang C, Hynes RO, Werb Z, Sudhakar A, Kalluri R: Physiological levels of tumstatin, a fragment of collagen IV alpha3 chain, are generated by MMP-9 proteolysis and suppress angiogenesis via alphaV beta3 integrin. Cancer Cell 2003, 3:589-601.

9. Isaacs JS, XU W, Neckers L: Heat shock protein 90 as a molecular target for cancer therapeutics. Cancer Cell 2003, 3:213-7.

10. Workman P: Pharmacogenomics in cancer drug discovery and development: inhibitors of the Hsp90 molecular chaperone. Cancer Detect Prev 2002, 26:405-10.

11. McCarthy MM, Pick E, Kluger Y, Gould-Rothberg B, Lazova R, Camp RL, Rimm DL, Kluger HM: HSP90 as a marker of progression in melanoma. Ann Oncol 2008, 19:590-4.

12. Sidera K, Patsavoudi E: Extracellular HSP90: conquering the cell surface. Cell Cycle 2008, 7:1564-8.

13. Stellas D, Karameris A, Patsavoudi E: Monoclonal antibody 4C5 immunostains human melanomas and inhibits melanoma cell invasion and metastasis. Clin Cancer Res 2007, 13:1831-8.

14. Sidera K, Gaitanou M, Stellas D, Matsas R, Patsavoudi E: A critical role for HSP90 in cancer cell invasion involves interaction with the extracellular domain of HER-2. J Biol Chem 2008, 283:2031-41.

15. Eustace BK, Sakurai T, Stewart JK, Yimlamai D, Unger C, Zehetmeier C, Lain B, Torella C, Henning SW, Beste G, et al: Functional proteomic screens reveal an essential extracellular role for hsp90 alpha in cancer cell invasiveness. Nat Cell Biol 2004, 6:507-14.

16. Sidera K, Samiotaki M, Yfanti E, Panayotou G, Patsavoudi E: Involvement of cell surface HSP90 in cell migration reveals a novel role in the developing nervous system. J Biol Chem 2004, 279:45379-88.

17. Glinskii OV, Huxley VH, Glinsky GV, Pienta KJ, Raz A, Glinsky W: Mechanical entrapment is insufficient and intercellular adhesion is essential for metastatic cell arrest in distant organs. Neoplasia 2005, 7:522-7.

18. Li W, Li Y, Guan S, Fan J, Cheng CF, Bright AM, Chinn C, Chen M, Woodley DT: Extracellular heat shock protein-90alpha: linking hypoxia to skin cell motility and wound healing. Embo J 2007, 26:1221-33.

19. Cheng CF, Fan J, Fedesco M, Guan S, Li Y, Bandyopadhyay B, Bright AM, Yerushalmi D, Liang M, Chen M, et al: Transforming growth factor alpha (TGFalpha)-stimulated secretion of HSP90alpha: using the receptor LRP$1 /$ CD91 to promote human skin cell migration against a TGFbeta-rich environment during wound healing. Mol Cell Biol 2008, 28:3344-58.

20. Johansson N, Ahonen M, Kahari VM: Matrix metalloproteinases in tumor invasion. Cell Mol Life Sci 2000, 57:5-15.

21. Egeblad M, Werb Z: New functions for the matrix metalloproteinases in cancer progression. Nat Rev Cancer 2002, 2:161-74.
22. Sternlicht MD, Werb Z: How matrix metalloproteinases regulate cell behavior. Annu Rev Cell Dev Biol 2001, 17:463-516.

23. Yang Y, Rao R, Shen J, Tang Y, Fiskus W, Nechtman J, Atadja P, Bhalla K: Role of acetylation and extracellular location of heat shock protein 90alpha in tumor cell invasion. Cancer Res 2008, 68:4833-42.

24. Banerji U, O'Donnell A, Scurr M, Pacey S, Stapleton S, Asad Y, Simmons L, Maloney A, Raynaud F, Campbell M, et al: Phase I pharmacokinetic and pharmacodynamic study of 17-allylamino, 17-demethoxygeldanamycin in patients with advanced malignancies. J Clin Oncol 2005, 23:4152-61.

25. Cruz-Munoz W, Sanchez OH, Grappa Di M, English JL, Hill RP, Khokha R: Enhanced metastatic dissemination to multiple organs by melanoma and lymphoma cells in timp-3-/- mice. Oncogene 2006, 25:6489-96.

26. Thomaidou D, Patsavoudi E: Identification of a novel neuron-specific surface antigen in the developing nervous system, by monoclonal antibody 4C5. Neuroscience 1993, 53:813-27.

27. Patsavoudi E, Hurel C, Matsas R: Purification and characterization of neuron-specific surface antigen defined by monoclonal antibody BM88. J Neurochem 1991, 56:782-8.

28. Sambrook J, Fritsch E, Maniatis T: Molecular Cloning: A Laboratory Manual. NY: Cold Spring Harbor Labs, 21989.

29. Mahajan VB, Pai KS, Lau A, Cunningham DD: Creatine kinase, an ATPgenerating enzyme, is required for thrombin receptor signaling to the cytoskeleton. Proc Natl Acad Sci USA 2000, 97:12062-7.

30. Syggelos SA, Eleftheriou SC, Giannopoulou E, Panagiotopoulos E, Aletras AJ: Gelatinolytic and collagenolytic activity in periprosthetic tissues from loose hip endoprostheses. J Rheumatol 2001, 28:1319-29.

31. Heimburg J, Yan J, Morey S, Glinskii OV, Huxley VH, Wild L, Klick R, Roy R, Glinsky W, Rittenhouse-Olson K: Inhibition of spontaneous breast cancer metastasis by anti-Thomsen-Friedenreich antigen monoclonal antibody JAA-F11. Neoplasia 2006, 8:939-48.

doi:10.1186/1471-2121-11-51

Cite this article as: Stellas et al:: Monoclonal antibody $4 C 5$ prevents activation of MMP2 and MMP9 by disrupting their interaction with extracellular HSP90 and inhibits formation of metastatic breast cancer cell deposits. BMC Cell Biology 2010 11:51.

\section{Submit your next manuscript to BioMed Central and take full advantage of:}

- Convenient online submission

- Thorough peer review

- No space constraints or color figure charges

- Immediate publication on acceptance

- Inclusion in PubMed, CAS, Scopus and Google Scholar

- Research which is freely available for redistribution
Biomed Central 